\title{
Zoopoéticas: tres escrituras animales
}

PABLO VERGARA Universidad de Buenos Aires - CONICET / pabvergara@gmail.com

\section{Resumen}

El artículo busca pensar algunos aspectos de las obras de los escritores Felisberto Hernández, Mario Levrero y Antonio Di Benedetto a partir de un corpus de textos breves y fragmentos de novela en los que se piensa el elusivo acto de la escritura a partir del uso de figuraciones animales. Se intenta definir a partir de esto lo que podría ser una «escritura animal» y desentrañar su posibilidad o imposibilidad. Este intento trae a un primer plano consideraciones particulares acerca del tiempo, y de la relación entre autor y obra, además de abrevar en ciertas consideraciones acerca de la animalidad y la filosofía vitalista de Derrida y Deleuze-Guattari respectivamente.

Palabras clave: Felisberto Hernández / Mario Levrero / Antonio Di Benedetto / poéticas / animalidad

\section{Zoopoetics: three animal writings}

Abstract

The articule aims to think some aspects of the literature of the southamerican writers Felisberto Hernández, Mario Levrero and Antonio Di Benedetto, taking as corpus small texts and fragments of each, posing the questions on the animal figuration they create to think about the elusive act of writing. It pretends to understand if something like an «animal writing» is possible. This attempt gives capital importance to some consideration about time and to the author-work relation, as well as it takes regards from Derrida's animality and Deleuze-Guattari vitalist philosophy.

Key words: Felisberto Hernández / Mario Levrero / Antonio Di Benedetto / poetics / animality

Recibido: 19/07/2018. Aceptado: 12/12/2018

Para citar este artículo: Vergara, Pablo (2019). Zoopoéticas: tres escrituras animales. El taco en la brea, 9 (diciembre-mayo), 34-45. Santa Fe, Argentina: UNL. DOI: 10.14409/tb.viig.8186 
escribir como un ratón traza una línea o mueve su cola, como un pájaro emite un trino, como un felino se mueve o duerme profundamente.

Gilles Deleuze y Claire Parnet, Diálogos.

El título de este trabajo entraña, paradójicamente, una imposibilidad y un intento (que es triple) de subvertir esa imposibilidad, de instaurar una excepción. Porque con cierta necesidad debemos preguntar ¿es posible una poética animal para la escritura literaria? Y de serlo, junto con ello, ¿en qué consistiría, cómo trabajaría, cómo se escribe como un animal, como un ratón, un pájaro o un felino? En ese como, por otro lado, está fijada parte de la dificultad del problema, porque si bien se pretende tratar de poética o poéticas animales estas no apuntan a establecer como punto de llegada un escribir como donde ese «como» sea la marca de una representación justa, de una reproducción fiel ni de una correcta mimesis del animal, que lo capte, o que lo atrape en su forma. El como debe pensarse más bien como la marca de una distancia antes que de un acercamiento y de un hacer antes que de un ser. Como la búsqueda «de la forma para la inmadurez» de Ferdydurque, que no consiste «en expresar en forma madura la inmadurez ajena, (...) describirla artística o científicamente» (Gombrowicz:18) esos sucesivos atrapamientos a los que se ve arrastrado su protagonista. Lo que queremos llamar escritura animal en este trabajo no trata de hacer una descripción acertada, ni artística ni científica, del animal o de varios animales, sino identificar una pulsión creativa difícil de asir, pero de cierta especificidad que se entregaría a considerar el acto de creación en relación con una vida, que miraría la forma literaria como una forma viviente o aproximativa de, y tendiente $a$, lo viviente. En un sentido más restringido intentaría captar en la creación literaria una búsqueda, por medio de la forma, de un animal (o de una planta) que sería interno a un movimiento de la escritura.

Por otro lado, una poética animal de este tipo quiere ser en tanto creación aquella que aporta o puede aportar un «pensamiento del animal» (Bailly), considerando "pensamiento» también en un sentido restringido: pensamiento que no se aparta de su forma sino que es (en su única esencia) forma, es decir, su expresión misma. Con esto, no quiere reducir lo animal a una pura dimensión sensato-discursiva, sino que intenta que la misma opacidad de la mirada animal caracterice este pensamiento: estaría guiado por la suspensión del saber sobre el animal y por su apertura, no plegado al saber sino desplegado en lo indeterminado del pensar.'

Presentamos y analizaremos en lo sucesivo tres textos breves, en dos casos pasajes de un texto mayor, y el tercero un breve prólogo-ensayo de poética. La extensión reducida de este corpus no obsta para poner a jugar una serie de elementos que se relacionan y se desvían de las creaciones de los tres autores. Cada uno por su lado trazan líneas que comunican las obras entre sí, si no de manera directa, al menos en aspectos que esperamos aclarar o mostrar con cierta suficiencia.

«Explicación falsa de mis cuentos» de Felisberto Hernández, publicado por primera vez en La licorne, la revista parisina de Susana Socca, en 1955, y suerte de prólogo forzado de «Las hortensias» en las obras completas del uruguayo reunidas por José Pedro Díaz entre 1981 y 1983; un fragmento de El discurso vacío (primera edición 1996), de Mario Levrero y un fragmento de Zama (1954) de Antonio Di Benedetto, son los textos en cuestión. Lo que los une, en sentido lato es que piensan o buscan pensar —o tal vez situarse en él para pensarlo - el elusivo acto de la escritura; en rigor, el de sus propias escrituras. A la dificultad de una supuesta o presentida «escritura animal» hay que agregar por lo tanto, la dificultad de pensar el acto de escritura escribiendo, el gesto de escribir sobre el propio acto de escritura presente en los tres textos-fragmentos. 
Fluidez, dinamismo y cierta vitalidad son tres notas comunes de los modos en que estos textos piensan la escritura: «Hay un fluir, un ritmo, una forma aparentemente vacía» (Levrero 1996:43); «Lo más seguro de todo es que yo no sé cómo hago mis cuentos, porque cada uno de ellos tiene su vida extraña y propia» (Hernández:176); «La disposición a escribir no es una semilla que germina en tiempo fijo. Es un animalito que está en su cueva y procrea cuando se le ocurre» (Di Benedetto:138-139). Por afán de orden presentaremos los textos de a uno.

\title{
Una escritura vigilante: Mario Levrero
}

Transcribo en extenso el pasaje que nos interesa de Levrero:

\begin{abstract}
25 de noviembre
Hay un fluir, un ritmo, una forma aparentemente vacía; el discurso podría tratar cualquier tema, cualquier imagen, cualquier pensamiento. Esa indiferencia es sospechosa; presiento que tras la apariencia de vacío hay muchas, demasiadas cosas. El vacío nunca me asustó demasiado; en ocasiones hasta llegó a ser un refugio. Lo que me asusta es no poder huir de ese ritmo, de esa forma que fluye sin develar sus contenidos. Por eso me pongo a escribir, desde la forma, desde el propio fluir, introduciendo el problema del vacío como asunto de esa forma, con la esperanza de ir descubriendo el asunto real, enmascarado de vacío.

No quiero forzar las cosas con imágenes del pasado o explicaciones de la situación presente, que siempre suenan falsas: me gustaría dejar hablar a esa forma para que se fuera delatando por sí misma, pero ella no tiene que saber que yo espero que se delate porque en seguida se me escurriría otra vez hacia la apariencia de vacío. Tengo que estar alerta, pero con los ojos entornados, con un aire distraído, como si no me importara el discurso que se va desarrollando. Es como entrar en un estanque con peces, y esperar que se aquieten las aguas agitadas y los peces se olviden de que algo agitó las aguas, y se acerquen, y comiencen a pasear su curiosidad próximos a mí y a la superficie del estanque; entonces podré verlos y, tal vez, atrapar alguno. (1996:43-44)
\end{abstract}

Una poética de Levrero, aún no desentrañada del todo, tiene lugar en el momento en que cierta disponibilidad se ha producido. La escritura para Levrero arranca cuando el tiempo, un tiempo no cronológico, así lo permite. Para que esto suceda a Levrero le toca esperar. El núcleo de la extensa cita es el final: «Es como entrar en un estanque con peces, y esperar que se aquieten las aguas agitadas y los peces se olviden de que algo agitó las aguas, y se acerquen, y comiencen a pasear su curiosidad próximos a mí y a la superficie del estanque; entonces podré verlos y, tal vez, atrapar alguno» (44). No es casual, la escritura de Levrero viene al final, cuando luego de una espera indeterminada algo ha sucedido y entonces se lo cuenta, se lo registra, se lo busca «atrapar». Levrero sabe que «atrapar» es lo difícil, lo más complicado y tal vez lo imposible. Esa dificultad rige el extenso proyecto (de alrededor de 20 años) de «La novela luminosa», del que El discurso vacío es casi una etapa, una posta (un puesto), una estación en el paciente transcurso de la espera a que las aguas se aquieten lo suficiente para ver y tal vez atrapar al pez. Se puede decir, en efecto, que Levrero escribe $E l$ discurso vacío en espera de que algo pase, o, lo que es lo mismo, padeciendo no tener nada que escribir, he ahí la razón del título de la novela. ${ }^{2}$

La persecución de la imagen que se forma en el interior del autor y que desencadena un cuento o una novela es una formulación anterior — de un «primer Levrero» si hubiera tal—de esta misma espera en función de que lo que tenga que advenir ocurra. ${ }^{3}$ Como se puede ver, es una situación 
paradójica o contradictoria porque no se espera nada en especial, o no se espera nada de nada, y sin embargo necesita de algo que suceda, sea una imagen que se tiene que formar, o algo que no es nada en particular — 0 , simplemente, una nada particular - que ocurra. Es una escritura del acontecimiento, que en tanto tal no es el suceder de algo, sino la efectuación del tiempo por sí mismo, su «liberación» (Deleuze-Guattari:270) por medio de un intervalo particular. Este "factor tiempo» (¿no le llamó así Adriana Astutti?) ${ }^{4}$ es clave tanto para la escritura de Levrero como, lo veremos, también para Hernández y Di Benedetto.

«Tengo que estar alerta, pero con los ojos entornados, con un aire distraído como si no me importara el discurso que se va desarrollando» (Levrero:43-44). La atención en espera de que ocurra o se desarrolle lo que tiene que ocurrir supone también una postura corporal. No es solo atender en abstracto a que ocurra una situación también abstracta. La mirada y el aire son las marcas de esta postura: mirada entornada, miope, y no directa ni límpida sino específica y lateral, al sesgo, estrábica. En apariencia de desatención pero atento, no a lo central, directo, sino a lo extraviado (lo que está fuera de la vista, de la vía, dejando vagar la mirada, desorientándose): no a lo que está enfrente sino a lo que aún no está ahí. La escritura en Levrero supone por tanto una disposición, tanto personal como exterior. Como si se tratara de una particular agrupación de elementos alrededor del escritor (un escritor que no está como tal, sino abstraído, disuelto, devenido receptividad), preparado aunque no específicamente, sin otra virtud que el estar ahí disponible, listo para actuar. Esa disponibilidad vigilante de la escritura de Levrero ha sido vista como un rasgo de su personalidad, un aspecto biográfico o de su figura de autor, pero no se ha considerado como un rasgo particular de su poética. En su libro Mario Levrero para armar. Jorge Varlotta y el libertinaje imaginativo (2013), Jesús Montoya Juárez intenta una primera biografía de Levrero a partir de entrevistas a familiares y amigos, y de un recorrido por los hitos personales de Varlotta Levrero. Perla Domínguez, una de las parejas de Levrero, en una entrevista inédita realizada por Montoya Juárez da una excelente definición de la disponibilidad levreriana, adjudicándola a un «atractivo» de la persona, pero valiéndose de un personaje de las historietas levrerianas para ejemplificarla, el Santo Varón publicadas en 1986, es decir, algunos años antes del «giro autobiográfico» de la literatura levreriana de "Apuntes bonaerenses» $\mathrm{y}$ «Diario de un canalla», de 1992: ${ }^{5}$

Jamás era aburrido, ni pesado, ni hablaba mucho, ni se repetía, ni forzaba nada. Hasta en lo más cotidiano funcionaba en este estado de... ¿descubrimiento? ¿Disponibilidad? No sé cómo llamarlo, pero él mostró de qué se trata en su muy autobiográfico Santo Varón, donde usted recordará que el personaje no hace absolutamente nada. Solo se limita a estar parado en una esquina... y empiezan a ocurrir cosas, que pueden ser nimias pero que como él no va, ni viene, ni está apurado, ni está pensando en otra cosa como hacemos casi todos casi siempre, las percibe, y las realza. Y lo más extraordinario es que nos llevaba a los demás a funcionar también así. (...) Por eso su compañía era... irremplazable. (Montoya Juárez:49)

Como acertadamente dice Domínguez, Santo Varón da cuerpo a ese rasgo (y postura) que es también parte de la escritura de Levrero. Los elementos son parecidos al pasaje del estanque de los peces: la espera, la vacancia, el olvido de disposiciones que alterarían una percepción limpia de aquello que pueda (o no) suceder: 
Olvido de pensamientos, deseos, necesidades permite el realce de esos momentos u objetos aparentemente anodinos mediante esa experiencia desinteresada.

Santo Varón es, de este modo, un personaje - pero también, vale decir, una criatura, un animal- ejemplarmente levreriano. Y no se debería caer tan fácil en reconocer a Levrero en Santo Varón o viceversa, porque la historieta dibujada por Lizán trata específicamente sus situaciones en un mundo más cercano al de la literatura, aunque sus conversaciones con vacas que van camino al matadero, con fantasmas, con moscas, desentrañen, a pesar de su rareza, la «máquina de la realidad» como sugirió Fogwill: «la irrupción del factor Levrero, ese entramado de manías que orientan a tratar el mundo real como una fantasía y a lo fantástico como al conjunto de piezas que dan cuenta del funcionamiento de la máquina de la realidad» (Astutti:203).

Un actuar, decíamos, que también tenemos que reconocer como deceptivo porque consiste en «dejar hablar» a la forma, dejar que «se delate por sí misma»: «ella no tiene que saber que yo espero que se delate porque en seguida se me escurriría otra vez hacia la apariencia de vacío» (1996:43). Esta postura-posición se completa con una imagen-metáfora de significación incierta: es como

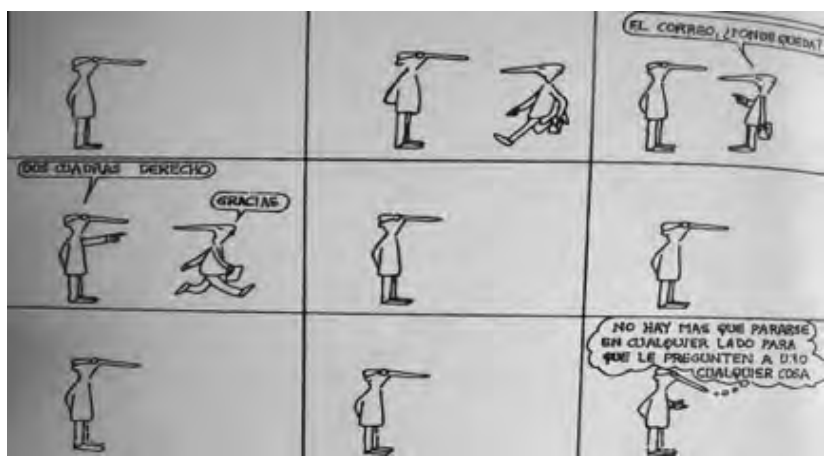

Figura 1, Santo Varón

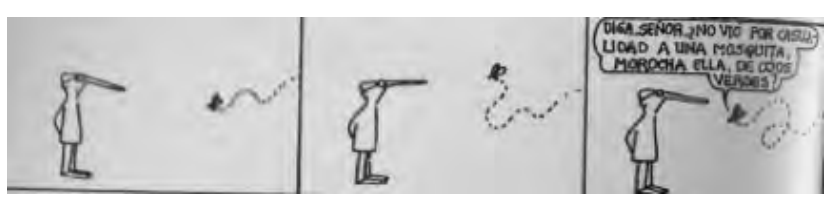

Figura 2, Santo Varón

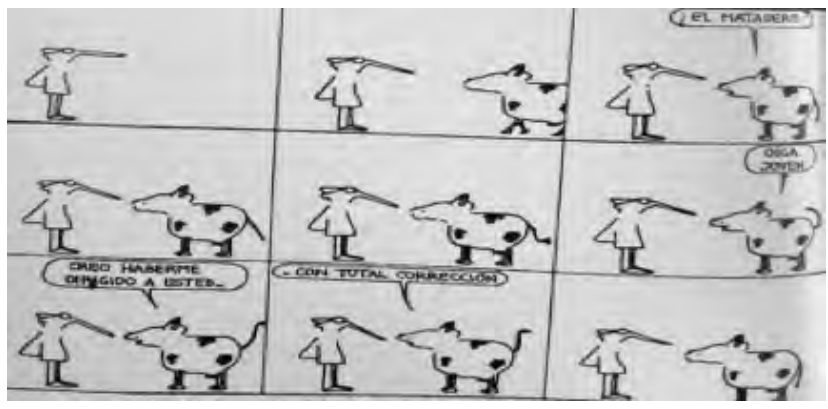

Figura 3, Santo Varón estar sumergido en el agua, esperando la disposición del elemento-medio y de los cuerpos-formas en movimiento: «Es como entrar en un estanque con peces y esperar a que se aquieten las aguas». Así como Levrero va dando intuitivamente —en acto se puede decir - la descripción de la búsqueda de su escritura, tanteando con palabras para dar con una imagen, imagen ajena, libre de concepto y de contenido incierto, la imagen del estanque de los peces concentra o logra captar por un momento aquello (el exceso) que busca y le es elusivo a una misma vez. En esta operación el "como» deja de ser un simple conector de analogía, un puente entre lo significado y lo significante. ${ }^{6} \mathrm{~A}$ pesar de que no quiero invocar en este punto ni implicar que lo que ocurre sea un devenir-animal a la Deleuze-Guattari, que supone bastante más que una mera apelación a una figura animal o hacer hablar a un perro o a un gato, sí quiero destacar del pasaje levreriano que en la concepción de la forma-imagen el conector «como» establece una relación tanto más compleja que la de una mera analogía, destacando, por un lado, su potencia de significación que excede en mucho la figura (retórica) de la comparación o del tropo metafórico; y por otro, la misteriosa capacidad de la escritura de acercarse diferencialmente hacia aquello a lo que tiende, pero siempre dejando la marca — justamente ese «como»— de lo desmesurado de la tentativa, es decir, de la inevitabilidad de que a los ojos del crítico no se trata más que de un procedimiento.

\section{Una escritura soberana: Felisberto Hernández}

Como cuentos-planta define Felisberto Hernández sus creaciones. «Explicación falsa de mis cuentos» es el texto por medio del cual intenta, a sabiendas del riesgo y de la imposibilidad de la 
tentativa, «explicar» sus cuentos, es decir, de contar, por la vía del qué y del cómo, la singularidad de sus creaciones, los elementos intrínsecos de estas y en última instancia el secreto de su escritura. A pesar de la falsedad de la explicación, se puede suponer que el intento es paradójicamente sincero: en primer lugar, reconoce que dará explicaciones que son irremediablemente «exteriores a ellos», es decir, que pone en primer lugar una distancia entre una explicación de la ficción y la ficción misma: de ahí lo falso de la tentativa. Pero, en segundo lugar, Hernández lleva la tentativa por donde él supone que debe ir, hacia el tema de la intervención de la conciencia en la escritura. Sus cuentos no son naturales, dice, es decir, escritos sin «intervención» de la conciencia, ni tampoco «dominados por una teoría de la conciencia»: «preferiría decir que esa intervención es misteriosa».

Para circundar el misterio interviene la imagen de la planta: «En un momento dado pienso que en un rincón de mí nacerá una planta». De un modo similar a Levrero, la escritura de Felisberto precisa de un momento previo indeterminado, al que sigue una determinación del tiempo por sí mismo, su irrupción por fuera de la línea cronológica, surgimiento de un momento dado. Temporalidad no buscada, no anticipable, e intervención del tiempo, despliegue de este sobre sí, en el que algo puede o está por suceder, «algo raro, pero que podría tener porvenir artístico. Sería feliz si esta idea no fracasara del todo. Sin embargo, debo esperar un tiempo ignorado: no sé cómo hacer germinar la planta, ni cómo favorecer, ni cuidar su crecimiento».

La posición o lugar del escritor es también de espera y receptividad. Pasividad antes que agencia. Se reduce a «cuidar», a asistir: «cuidar que no ocupe mucho espacio, que no pretenda ser bella o intensa, sino que sea la planta que ella misma esté destinada a ser, y ayudarla a que lo sea». Lejos de una figura de autor elevada, potente (un prestigioso autor-creador), el escritor es como un jardinero, un cuidador de plantas, un auxiliar en el crecimiento de otra vida (de una vida menor), la que se desenvuelve por sí misma, sin intervenciones («no hará mucho caso si él quiere sugerirle demasiadas intenciones»), pero sin conocimiento reflexivo, sin conciencia de sí: «Si es una planta dueña de sí misma tendrá una poesía natural, desconocida por ella misma», «Ella misma no conocerá sus leyes aunque profundamente las tenga y la conciencia no las alcance», «la conciencia intervendrá, pero en última instancia impondrá su voluntad». La marca más notoria de la sinceridad de la «Explicación falsa» de Felisberto está en la insistencia, en el retorno de otro "factor», del "factor conciencia», del problema que significa para la creación. La conciencia interviene, reconoce, pero se procura mantenerla a raya, no dejar que domine la escritura. Solo así estos cuentos-planta alcanzarán «su vida extraña y propia. Pero viven peleando con la conciencia para evitar los extranjeros que ella les recomienda» (llamativa expresión inmunitaria: la conciencia recomienda extranjeros que la planta rechaza).

Tiempo dado, paciencia y pasividad, atención y asistencia, cuento-vida que debe crecer, desarrollarse y llegar a ser soberano de sí mismo. Una planta que brota y crece, por sí misma y dueña de sí misma. Quisiera agregar acá un matiz teórico. Crecer y ser dueño de sí mismo, ser soberano y reinar sobre sí, dice Derrida, es lo que Heidegger denomina el walten (traducido habitualmente como reinar, gobernar) de la naturaleza y de la physis en su sentido más originario de «totalidad de lo que es» (Derrida 2006:68): el reinar de la naturaleza como Reino, antes de cualquier determinación política. Walten, «reinar», «gobernar», hacer uso de una fuerza soberana, pero también «crecer», «autodesarrollarse», ocupará insistentemente a Derrida en la segunda parte del seminario "La bestia y el soberano» pues en relación con este infinitivo ve Derrida que Heidegger produce un efecto «violento», un uso también soberano de fuerza en su discurso para establecer y fijar la diferencia entre el dasein constructorde-mundo del hombre y el ser pobre-de-mundo del animal. Lo que sospecha Derrida es que todo el 
edificio teórico heideggeriano respecto del mundo, del hombre y del animal, se sustenta en una decisión soberana del propio Heidegger (de una walten heideggeriana) de hacer brotar, crecer y mantener esa diferencia entre el dasein humano y el animal, que no tendría otro fundamento que esa decisión. ${ }^{8}$

Es por lo menos curioso que en los dos textos revisados hasta acá, el escritor (¿no podríamos llamarlo meramente el escriba o el escribiente?) no interviene más que mínima o lateralmente. Sin embargo, ¿no es quien escribe y produce todo aquello que ha escrito? Como sea, él no es el soberano. No cede su soberanía, pero en el momento en el que la ejecuta no la posee, no la tiene para sí, no sabe nada de ella cuando escribe; y cuando no escribe, es impotente respecto de ella. ${ }^{9}$ Aún más, Hernández experimenta en este breve texto «falso» que todo acto de escribir es un acto de desposesión y de disolución: de forma sutil, mientras escribe la «Explicación falsa» pierde su persona y pasa del yo a él: «Al mismo tiempo ella crecerá de acuerdo a un contemplador al que no hará mucho caso si él quiere sugerirle demasiadas intensiones o grandezas».

«Lo más seguro de todo es que yo no sé cómo hago mis cuentos». La marca de la sinceridad de la «Explicación...», el factor conciencia como le llamamos, es también la marca de esa impotencia del escritor. Para un lector avisado de Felisberto Hernández, la «Explicación falsa...» podría parecer por lo menos un texto insuficiente o, yendo un poco más lejos, malogrado en el despliegue del problema, despistado, perdido en un desvío (otro extra-vío) que no debería revestir mayor importancia: la pugna entre una conciencia tutora y «algo raro» que busca desarrollarse sin tutoría ninguna. Y sin embargo, la explicación no miente: dice con la claridad de lo que no se deja decir en forma directa que lo soberano es la escritura, que lo que tiene el poder de crecer (walten) es la planta y que ese poder que no tiene tiempo definido ni pertenece a nadie.

\section{Un animal cualquiera. Di Benedetto}

El pasaje de Zama que quiero comentar lo presento dividido en tres partes, a pesar de que en la novela corresponde a una única secuencia (la última del capítulo 24, segunda parte, páginas 138-140). Zama prepara un memorándum solicitado por el gobernador sobre Manuel Fernández, el escribiente de la gobernación que cuando se le requirió para que escribiera una solicitud al rey que era favorable a Zama fue sorprendido... sorprendido escribiendo; cuando se le pregunta qué escribía, este responde, «un libro» (136). El Gobernador quiere saber por qué Fernández escribe un libro, es decir algo inapropiado al lugar y al tiempo en los que debería estar dedicado al servicio del rey. Le encomienda la tarea a su asesor letrado, a Zama:

Le pregunté, amistosa y reservadamente, en la oficina que él ocupaba, por qué escribía en la casa de la gobernación, es decir, donde su tiempo debía estar consagrado enteramente a los servicios del rey. Me respondió de manera ambigua.

—La disposición de escribir no es una semilla que germina en tiempo fijo. Es un animalito que está en su cueva y procrea cuando se le ocurre, porque su época es variable, pues unas veces es perro, otras hurón, unas veces es pantera y otras conejo. Puede hacerlo con hambre, o sin hambre, en ocasiones sólo si está muy reposado, en otras si le duele una herida del cazador o si regresa excitado de una jornada de fechorías.

Presté suma atención a su discurso y luego, asintiendo, dije:

—iAá! (138-139)

La respuesta de Fernández es sorprendente — no solo a Zama sorprende, quien apenas puede 
disimular su desconcierto con la interjección vaga y un tanto idiota «ijál»—, sorprende por su complejidad y elaboración (y por su belleza), por la contestación que da a una pregunta que se pretendía simple, retórica, pues lo que había bajo su forma era un llamado de atención y la exigencia de una disculpa que evidenciara la falta en la que había incurrido Fernández.

Escribir, dice Fernández, es dar lugar y curso a una vida cualquiera. No se refiere a un animal en particular sino a una vida compleja y frágil, y por tanto exigente. Un animal esquivo (que habita escondido) pero que sale cuando le conviene, «porque su época es variable, pues unas veces es perro, otras hurón...» pantera, conejo (139). Al factor tiempo ya considerado en los pasajes anteriores, Fernández —o Di Benedetto debiéramos decir-agrega otra dimensión no-medida de tiempo donde la escritura ya no pide únicamente su tiempo propio, sino que además cada lapso hace posible, determina y modifica, la escritura. Informa o individúa a ese animal que «varía según épocas» (¿y qué podemos entender aquí por «época» sino esos períodos incuantificables pero definidos, interválicos, de tiempo, haecceidades de tiempo, siguiendo a Deleuze y Guattari?). ${ }^{10}$ Acá no se trata solo de atender, de esperar como Levrero, a que advenga un tiempo para la escritura (a que algo se forme y crezca, en Felisberto Hernández), sino que ese tiempo indefinido, sin medida y singular, exige a su modo a la escritura ser captado por ella, se introduce en ella. Di Benedetto, decíamos, integra una nueva dimensión al factor-tiempo de Hernández y Levrero, y lo complejiza exponencialmente, porque ya no se trata de la forma de esa vida soberana que crece, un animal o planta que sería igual a sí mismo, sino también de los afectos que la modifican en cada momento. Ya no se trata de un pez o de una planta, sino de un animal quodlibet, de un animal cualsea enfrentado a su deseo," que se ve constantemente modificado por estar relacionado con un medio y aconteceres que lo afectan (hambre, reposo, dolor o excitación producto del sabor de la sangre). ${ }^{12} \mathrm{Di}$ Benedetto no solo se aleja de cualquier mimesis animal con un animal en trance de variación, sino que se adentra con profundidad en el «escribir como» del epígrafe. No se está hablando del animal exterior, sino de una exigencia cambiante y soberana que adquiere vida (vale decir, su potencia) cuando es escuchada, sentida, por el escritor, quien capta sus tiempos siguiendo sus variaciones libidinales. ${ }^{13}$

Pero el pasaje continúa, de esta manera:

Atraída en parte su confianza, le pedí que me mostrara unas páginas. Consintió en hacerlo y leí algunos párrafos con detenimiento, porque el pensamiento aparecía enrevesado.

Tuve que declararle:

—Pero esto es incomprensible!...

- Señor doctor, es posible que el primer hombre y el primer lagarto fueran incomprensibles para todo cuanto los rodeaba. Yo no sólo escribo: hago mi creación.

Lo observé ligeramente admirado. Después pretendí aconsejarlo:

一iNadie lo aceptará!

Me cortó, arrogante:

-Vuesa merced, para escribir mi libro no tengo amo.

- ¿Y la censura?

El animal cualsea —en este punto, este podría ser el nombre del proyecto de escritura de Fernández o Di Benedetto- no se somete a otra fuerza que a la que proviene de la escritura. De ahí que su resultado parezca incomprensible para Zama, y que Fernández desestime medirlo con el ojo crítico 
del asesor letrado. La soberbia del escribiente queda manifiesta con su réplica: si es incomprensible lo que ha escrito es porque la lectura de Zama se asemeja a la observación, con una mirada caduca, de un animal nunca visto, «incomprensible para todo cuanto lo rodea», extraño no solo en virtud de su desemejanza respecto de lo que se ha visto (y Fernández se refiere a la forma literaria), sino también de la potencia de su diferencia y de la autonomía con que se lo ha escrito: sin amo. Animal-escritura que, podemos pensar, no es tanto un desafío para la imaginación como para el pensamiento, otra exigencia de la escritura. ${ }^{14}$ Habría que hacer aquí un paréntesis para contrastar estas afirmaciones del secretario de la gobernación con algunos fragmentos de los prólogos de Di Benedetto a sus obras anteriores a Zama (Mundo animal, de 1953, y El pentágono, de 1954, segunda edición de 1974) donde el joven escritor mendocino — de una edad que podemos aproximar a la de Manuel Fernández — habla de «literatura evolucionada» (1953:9), como si tratara en clave darwiniana de otro animal futuro, y contra la saturación «de novela tradicional» (1974:12). Escribir sin amo y sin tiempo ni lugar apropiado ya habría de costar el puesto a Fernández, sin embargo Zama, sin ánimo de hundirlo más, más bien intrigado por lo que lee y no puede comprender, y preocupado por la suerte del secretario, quiere saber cómo es posible tanto arrojo, tanta exposición al peligro: «¿Y la censura?»:

-Escribo porque siento necesidad de escribir, de sacar afuera lo que tengo en la cabeza. Guardaré los papeles en una caja de latón. Los nietos de mis nietos los desenterrarán. Entonces será distinto.

Pensé que era un egoísta. Pensé también que, quizá, dentro de ciento cincuenta años, al abrirse la caja, habría otras formas de restricciones y censura. (139)

Esta tercera parte de una secuencia que como se dijo es continua en la novela, aporta un último aspecto al pensamiento de la literatura de Di Benedetto, un último matiz a la soberanía de la escritura. El tiempo de la obra no es por fuerza sincrónico con el de su escritura. Otro elemento de la impotencia del escritor frente a su creación, de la escritura como «poder del que no puede disponerse», de su exigencia central, como ha escrito Blanchot (ver nota 10), toma la forma de un problema de lo contemporáneo, de los tiempos irreductibles que coexisten en la literatura y el arte. El destino próximo de la escritura de Fernández es una caja de latón en espera de que llegue el tiempo para la obra. Nuevamente Fernández habla como en un espejo invertido por Di Benedetto y por Zama. La novela futura de Fernández encontrará su lugar en ciento cincuenta años o en cuatro generaciones, mismo tiempo en que Zama verá la luz como una novela del pasado, sembrada de anacronismos distorsivos. Esto no paraliza al escritor ni lo consuela, sino que indaga en aquello que Aira llamó «las tres fechas», de «la fuga hacia delante», de la escritura, de toda obra literaria, de toda obra de arte. Del mismo modo, piensa Zama, es probable que la censura siga existiendo aunque no será la misma: permanencia y cambio; presente perpetuo e inaprehensible que contiene pasado y futuro en un solo tiempo, en un solo objeto. El riesgo de escribir a los que no escapó Di Benedetto y que lo convirtió en un héroe salido de su propia obra. Y el epígrafe de la novela, profético, misterioso, ominoso, «A las víctimas de la espera», alcanza también al animal cualsea de su escritura, porque es un epígrafe dirigido a un cualsea, a una víctima innombrada, impersonal, más colectiva que plural, aún víctima, encerrada en el tiempo de la promesa.

Hasta aquí hemos revisado los tres pasajes o textos breves, textos-fragmento, seleccionados para circundar el problema de una posible escritura animal. Lo que se ha pretendido es captar cómo el 
pensamiento de la escritura como una especie de cuerpo que vive implica toda una teoría poiética que si bien no es compartida y es en los tres casos diferente, contiene elementos en común y que se desarrollan, y esto es quizás lo más importante, atendiendo a un horizonte de problemas en común.

El factor tiempo, en primer lugar, es algo que queda tematizado en estos tres intentos, como la «irrupción» (sabemos que es palabra levreriana por antonomasia) de una temporalidad extraña en la linealidad cronológica, que interrumpe el paso medido del tiempo y lo substituye con un tiempo no pulsado de la escritura. El mismo tiempo, como demuestra Di Benedetto con su animal cambiante, impone sus determinaciones particulares a la escritura: es el tiempo lo que se hace escritura cuando el tiempo de la escritura adviene. Así también debemos entender la espera vigilante de Levrero devenido agua en el estanque de los peces. No en vano la metáfora clásica del tiempo que corre (tiempo de Cronos) es la del agua del río que no es nunca la misma en el mismo punto: con la intuición de los grandes escritores, Levrero piensa su escritura en un agua detenida, el agua de un estanque en la que el observador espera su aquietamiento y busca diluirse en ella: tentativa no realizable sino como gesto, esa es la exigencia de la escritura.

Por su parte, Felisberto, tal vez entrampado en el problema de la conciencia (pero entrampado falsamente porque su breve texto no llega a encubrir del todo su sesgo irónico) y en la intervención de este factor en la escritura, que también puede ser visto como un problema de época pues las lecturas del psicoanálisis ya habían entrado y comenzado a impregnar el campo literario en ambos márgenes del Plata, con el pensamiento de la ficción-planta pone en primer plano el problema del crecimiento y soberanía de la escritura en contraste con un autor aminorado, desposeído por el acto mismo que lo constituye. En apariencia el autor-creador que propone Manuel Fernández en Zama estaría en las antípodas del de Felisberto, pero el animal de la escritura se encarga de salvar esa distancia recordando que para escribir no hay tiempo fijo porque se escribe cuando ese «animalito» así lo pide o exige. El escritor —y en este sentido Hernández y Fernández, o Di Benedetto, están del mismo lado- es quien sigue y persigue, o quien vigila y asiste al animal. Sea cual sea la figura, planta o hurón, es quien está detrás de este, quien va a la siga, en pos del animal de la escritura, el que es anterior en un doble sentido: el animal es quien está antes (antes que el hombre también nos recuerda Derrida en otra parte) ${ }^{15}$ y quien está más allá, inalcanzable, porque no sabemos, no hay saber para decir qué es, sólo acercamiento y rodeo ya que no es un animal conocido (animal del saber) sino uno cualquiera, uno cualsea, animal siempre cambiante y por venir.

El poder de autor - creador que cree poseer Manuel Fernández cuando habla con Zama se refiere no a su superioridad respecto del animal de la escritura, sino tan solo al poder de seguir el camino a la caza de este sin obedecer a otra regla ni amo que aquel que impone esa misma persecución. La soberanía del escritor no se ejerce sobre la obra, sino que es aquella quien manda a este perseguir la obra en cada momento y lugar que le sea propicio o necesario. Es por lo tanto una soberanía que esconde solo parcialmente la impotencia del escritor-auxiliar hernandiano y del vigía levreriano. Y, a la inversa, aunque estos luzcan su impotencia, también poseen y hacen uso de ese poder de la escritura del que se enorgullece Manuel Fernández. Es también la soberanía del tiempo de la escritura y del arte, tiempo Aiôn, ${ }^{16}$ del lujo improductivo (del otium), sobre el tiempo productivo (del nec-otium), el tiempo organizado de Cronos, el tiempo regio de la gobernación y del Estado, en el que trabajan Zama y Fernández. 


\section{Notas}

1 «La mirada mira, y esa es en ella la vía del pensamiento, o al menos de un pensamiento que entonces no se pronuncia, no se enuncia, pero que tiene lugar y se ve que se mantiene en ese lugar puramente extraño y extrañamente ilimitado que es la superficie del ojo» (Bailly:30).

2 En una carta inédita a Hebert Benítez Pezzolano, Levrero se explica de esa forma acerca del título de la novela. Agradezco a Hebert Benítez el haberme mostrado ese valioso documento (Comunicación personal, agosto 2017).

3 Levrero acostumbraba a decir en entrevistas que sus textos estaban hechos a partir de imágenes (ver Levrero —1992 — y Silva Olazábal —15 y ss-). En su cuento «Los muertos» esta teoría está tematizada con la observación de los dibujos de una tela -otra figura del tapiz- desde la cual emerge un relato. (1987:261).

4 Dice Astutti: «El problema es como darle un tiempo al acontecimiento» (209), tiempo marcado por interrupciones e irrupciones. Remito a este texto de Adriana Astutti para una lectura más completa y pormenorizada del tiempo en el Levrero de La novela luminosa.

5 Aunque hay que decir que el "proyecto» de La novela luminosa se remonta al menos a 1984. Ver Astutti (218-219).

6 «La palabra "como" forma parte de esas palabras que cambian singularmente de sentido y de función desde el momento en que se las convierte en expresiones de devenires y no en estados significados ni relaciones significantes» (DeleuzeGuattari:276).

7 Se trata de un texto que apenas supera una página de extensión. Todas las citas corresponden a Hernández (175-176).

8 Ver La bestia y el soberano. Volumen II, entre otras 58, 66-72, $143,145,158-60$.

9 Blanchot sobre Kafka: «El sentimiento de que esa incertidumbre - el hecho de que escribir no es un poder del que pueda disponerse - pertenece a lo que hay de extremo en la obra, exigencia central, mortal que "por desgracia no es la muerte", que es la muerte pero mantenida a distancia, los tormentos eternos del morir» (139).

10 «Existe un modo de individuación muy diferente del de una persona, un sujeto, una cosa o una sustancia. Nosotros reservamos para él el nombre de haecceidad. Una estación, un invierno, un verano, una hora, una fecha, tienen una individualidad perfecta y que no carece de nada, aunque no se confunda con la de una cosa o de un sujeto. Son haecceidades, en el sentido de que en ellas todo es relación de movimiento y reposo entre moléculas o partículas, poder de afectar o ser afectado. (...) no son simplemente ordenamientos, sino individuaciones concretas válidas por sí mismas y que dirigen las metamorfosis de las cosas y de los sujetos» (Deleuze-Guattari:264-265).

11 «Ese ser que viene es el ser cualsea, el factor quodlibet, algo que corrientemente se interpreta como señal de indiferencia, cuando en realidad debiera leerse, en ese quodlibet, el ser, tal que, sea cual fuere, importa, lo cual es algo muy distinto. Es una presentación efectiva de la diferencia, en la medida en que el reenvío a la voluntad (libet) nos muestra que el ser quodlibet está en relación original con el deseo. El cualsea no es una singularidad indiferente a la propiedad común (ser mendocino, masculino, mordaz), sino sólo en su ser tal cual es; con ello, la singularidad se desprende del falso dilema de la inefabilidad del individuo enfrentado al imperativo universal. El cualsea no se define en relación a otra clase, sino respecto de la pertenencia misma y el componente libidinoso, el libet del cualsea, no es nunca traducción de algo concreto, sino traducción de una traductibilidad. No es punto sino pasaje. Ese movimiento de anamnesis libidinal transporta el objeto del deseo hacia su mismo tener lugar, hacia la Idea» (Antelo:5-6).

12 Otra vez Di Benedetto entra en consonancia con Deleuze. El animal de la escritura de Fernández, a veces con hambre, a veces con sueño, se parece a la pulga deleuziana: «Ser una pulga de mar que unas veces salta y ve toda la playa, y otras permanece con la nariz enterrada en un solo grano de arena». (DeleuzeParnet:86).

13 A este animal cualsea podríamos también dar esta definición intentada por Derrida: “La-Vida-Animal”, ya hay ahí una multiplicidad heterogénea de seres vivos, más concretamente (pues decir "seres vivos" es ya decir demasiado o no lo bastante), una multiplicidad de organizaciones, de relaciones entre lo vivo y lo muerto, unas relaciones de organización y desorganización entre unos reinos cada vez más difíciles de disociar dentro de las figuras de lo orgánico y lo inorgánico, de la vida y/o de la muerte. A la vez íntimas y abisales, esas relaciones no son nunca completamente objetivables». (2008:48).

14 Una vez más Di Benedetto sorprende por su sintonía con los problemas contemporáneos suyos de la relación hombre/ animal: la imagen del primer lagarto o del primer hombre guar- 
da relación estrecha con lo escrito por Bataille en «La intimidad perdida»: en las pinturas de animales de Lascaux, Bataille reconoció el nacimiento del arte como la posibilidad de aparición de la experiencia. La pintura de la piedra acerca un conocimiento del animal, a la par que aleja una relación originaria (en el sentido de no mediada) con este. Ver Bailly (24-25).

15 El animal que luego estoy si(gui)endo (25-26). 16 Deleuze-Guattari (264 y ss).

\section{Referencias bibliográficas}

Aira, C. (2001). Las tres fechas. Rosario: Beatriz Viterbo.

Antelo, R. (2016). El glosador. Conferenecia leída en las «Jornadas de Homenaje a Antonio Di Benedetto», UNCuyo, Mendoza, 2016. http://www.academia.edu/34775876/ANTELO_El_glosador.pdf

Astutti, A. (2013). Escribir para después: Mario Levrero. En La máquina de pensar en Mario, De Rosso, E. (Selec.). Buenos Aires: Eterna cadencia, 201-222.

Bailly, J.-C. (2007). El animal como pensamiento. Santiago de Chile: Metales Pesados, 2014. Traducción de L. Felipe Alarcón.

Bataille, G. (1955). Lascaux o el nacimiento del arte. Córdoba: Alción, 2013. Traducción de Áxel Gasquet.

Blanchot, M. (1981). De Kafka a Kafka. Buenos Aires: Breviarios/Fondo de Cultura Económica, 1993. Traducción de J. Ferreiro.

Deleuze, G. y Parnet, C. (1977). Diálogos. Valencia: Pre-textos, 2013. Traducción J. Vásquez Pérez.

Deleuze, G. y Guattari, F. (1980). Mil mesetas. Capitalismo y esquizofrenia. Valencia: Pre-textos, 2006. Traducción de J. Vásquez Pérez y U. Larraceleta.

Derrida, J. (2006). El animal que luego estoy si(gui)endo. Madrid: Trotta, 2008. Traducción de C. de Peretti y C. Rodríguez Marciel.

(2010). Seminario La bestia y el soberano. Volumen II (2002-2003). Buenos Aires: Manatial, 2011. Traducción de L. Ferrero, C. de Peretti y D. Rocha.

Di Benedetto, A. (1954). Zama. Buenos Aires: Adriana Hidalgo, 2009.

Gombrowicz, W. (1961). Ferdydurke. Buenos Aires: El cuenco del plata, 2015. Traducción del autor y de un comité de traducción.

Hernández, F. (1955). Explicación falsa de mis cuentos. En Obras completas, Vol. 2. Buenos Aires: Sudamericana, 2010, 175-176.

Levrero, M. (1996). El discurso vacío. Buenos Aires: Interzona, 2006.

(1992). Entrevista imaginaria con Mario Levrero. En El portero y el otro. Montevideo: Arca, 169-187.

(1987). Los muertos. En Espacios libres. Montevideo: Puntosur, 245-275.

Levrero, M. y Lizasoain, J. (1983). Santo varón. En Levrero, M. (2016). Historietas reunidas de Jorge Varlotta. Montevideo: Criatura Editora.

Montoya Juárez, J. (2013). Mario Levrero para armar. Jorge Varlotta y el libertinaje imaginativo. Montevideo: Trilce.

Silva Olazábal, P. (2008). Conversaciones con Mario Levrero. Montevideo: Trilce. 